Revista Universo Contábil, ISSN 1809-3337

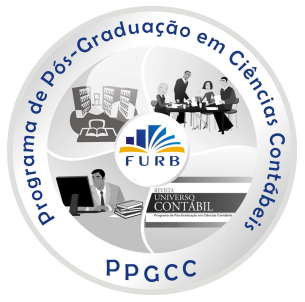

REVISTA CONTABILIDADE \& FINANÇAS - USP: UMA ANÁLISE DO PERFIL DA PRODUÇÃO CIENTÍFICA DE 1989 A 20091

\title{
ACCOUNTING \& FINANCE JOURNAL - USP: AN ANALYSIS OF SCIENTIFIC PRODUCTION PROFILE FROM 1989 TO 2009
}

\author{
Antônio Carlos Brunozi Júnior \\ Mestrando em Administração Pública do PPGAd/UFV \\ Professor do Departamento de Administração da Universidade Federal de Viçosa \\ Endereço: Campus da Universidade Federal de Viçosa \\ CEP: 36570-000 - Viçosa/MG - Brasil \\ E-mail: antonio.brunozi@ufv.br \\ Telefone: (31) 3899-1593
}

Magnus Luiz Emmendoerfer Doutor em Ciências Políticas pela UFMG Professor do Departamento de Administração da Universidade Federal de Viçosa Endereço: Campus da Universidade Federal de Viçosa CEP: 36570-000 - Viçosa/MG - Brasil E-mail:magnus@ufv.br Telefone: (31) 3899-2886

Luiz Antônio Abrantes

Doutor em Administração pelo PPGA/UFV Professor do Departamento de Administração da Universidade Federal de Viçosa Endereço: Campus da Universidade Federal de Viçosa

CEP: 36570-000 - Viçosa/MG - Brasil E-mail: abrantes@ufv.br. Telefone: (31) 3899-1593

Thiara Contelli Klein Graduada em Comunicação Social pela Universidade Federal de Viçosa Endereço: Campus da Universidade Federal de Viçosa CEP: 36570-000 - Viçosa/MG - Brasil E-mail: thiarack@yahoo.com.br Telefone: (31) 3892-5935

\footnotetext{
1 Artigo recebido em 13.01.2010. Revisado por pares em 15.07.2010. Reformulado em 16.01.2011. Recomendado para publicação em 24.01.2011 por Ilse Maria Beuren (Editora). Publicado em 31.10.2011. Organização responsável pelo periódico: FURB.
} 


\section{RESUMO}

Este estudo analisa a distribuição, as características metodológicas, a evolução e a temática das publicações científicas em periódico de contabilidade e finanças, bem como a produção de seus autores. O período pesquisado foi de 1989 a 2009, na Revista de Contabilidade \& Finanças da Universidade de São Paulo. A pesquisa de caráter descritivo analisou 354 artigos publicados nos 20 anos de existência do periódico. A avaliação da revista indicou a concentração de autores afiliados a USP, principalmente docentes doutores; entretanto, a partir de 2003 observa-se a participação de outras entidades nas publicações. O periódico apresentou evolução ao longo dos anos, sendo que se percebe a distinção das temáticas propostas nos artigos. Neste contexto, verifica-se a predominância de estudos relacionados a Finanças e Contabilidade (29\%), Ensino de Contabilidade e Conhecimento (13\%), Contabilidade Clássica e Teoria da Contabilidade (12\%) e Sistemas de Informação, Comunicação e Evidenciação (11\%). Quando se considera a proposta metodológica diversificada dos estudos observa-se quanto aos fins, a endogenia de trabalhos descritivos, principalmente no que concerne aos primeiros anos da revista. Quanto aos meios, notou-se entre 1989 e 2002, uma concentração de publicações de cunho bibliográfico e documental. O cenário é distinto entre 2003 e 2009, em que predominaram estudos realizados com aporte de dados primários e/ou secundários, podendo-se classificá-los como empíricos.

Palavras-chave: Contabilidade. Finanças. Pesquisa científica. Revista Contabilidade \& Finanças - USP.

\section{ABSTRACT}

This study examines the distribution, the methodological characteristics, evolution and topics of scientific publications in a journal of Accounting and Finance, as well as the production of their authors. The period studied was from 1989 to 2009, based on the Accounting \& Finance journal from the University of São Paulo. The descriptive study examined 354 articles published in the 20 years of existence of the journal. The evaluation of the journal indicated the concentration of authors affiliated with USP, mainly doctor professors; however, from 2003 on the participation of other entities can be noticed in the publications. The journal presented evolution over the years, being possible to notice the distinction of the themes proposed in the articles. In this context, there is a predominance of studies related to Finance and Accounting (29\%), Accounting Education and Knowledge (13\%), Classical Accounting and Theory of Accounting (12\%) and Information Systems, Communication and Disclosure $(11 \%)$. When considering the diversified methodology proposal of the studies, it is observed on the purposes the endogenous of descriptive studies, especially in the early years of the Journal. Regarding the means, it was noticed from 1989 to 2002 a concentration of bibliographic and documentary publication. The scenario is different in the period from 2003 to 2009, in which the studies conducted with the contribution of primary and / or secondary data predominate, which can be classified as empirical.

Keywords: Accounting. Finance. Scientific research. Accounting \& Finance Journal-USP.

\section{INTRODUÇÃO}

A produção científica faz parte de um ciclo que percorre a geração de idéias, o desenvolvimento da pesquisa e a comunicação. Essa comunicação é que impulsiona os progressos científicos, tecnológicos e culturais do país (MOURA, 2002). Segundo Lakatos e Marconi (2006), a pesquisa se constitui no caminho que permite conhecer a realidade ou 
descobrir verdades parciais. Esta pode ser considerada um procedimento formal no qual se faz presente o método de pensamento reflexivo, que requer um tratamento científico. Seu objetivo reside em encontrar respostas aos questionamentos por meio de processos da ciência.

No Brasil, segundo dados dispostos pelo Ministério da Educação (2009) tem-se observado um incremento da pesquisa e da publicação científica, decorrente do aumento de professores e pesquisadores titulados, aumento na participação dos docentes em congressos nacionais e internacionais, expansão dos cursos de pós-graduação (lato e stricto sensu) e da própria exigência concebida pelos órgãos governamentais para que os docentes vinculados aos programas de pós-graduação tenham publicações científicas relevantes.

Neste sentido, como afirmam Silva et al. (2005), o desenvolvimento da ciência e tecnologia nacionalmente, derivado de uma atitude dirigida à investigação, motivou, concomitantemente com outros fatores, aumento nas publicações nas distintas áreas da ciência. Sendo que a publicação científica é o resultado final de um complexo processo, que começa quando alguém crê que pode acrescentar novos achados ao conjunto de conhecimentos solidamente conhecidos.

Quando se considera a produção científica em Ciências Contábeis e Finanças, pode-se notar que a maioria do conhecimento que é produzido são trabalhos realizados nos cursos de pós-graduação. Todo o material desenvolvido aumenta a divulgação da aplicabilidade da Contabilidade, como forma de prover seus usuários de informações úteis, tempestivas e auxiliares do processo decisório, em qualquer âmbito empírico que se faça necessário.

A veiculação pela qual se processam essas comunicações científicas são descritas em livros, periódicos, teses, dissertações, anais de congressos. A publicação de trabalhos é uma das formas mais importantes de disseminação do conhecimento científico, considerando um determinado assunto de estudo. As contribuições decorrentes dessas publicações são notórias, principalmente a quem enseja seguir o caminho da pesquisa científica.

Observa-se assim a importância da produção científica na área financeiro-contábil, que por meio dos periódicos e outros meios de divulgação científica levam esses estudos ao conhecimento dos leitores, demonstrando uma conceituação que serve de suporte para que haja uma possibilidade cada vez maior avanço no desenvolvimento científico. A importância dessa opção de investigação fundamenta-se na contribuição para o entendimento da produção do conhecimento na área de Contabilidade e Finanças, a partir de suas características, que são constituídas por meio dos dados de autoria, citação, referências, métodos, dentre outros.

Atualmente, considerando a importância do conhecimento da pesquisa científica, temse utilizado procedimentos que avaliam a produção da própria ciência, no intuito de mensurar a qualidade dos estudos nos âmbitos de divulgação. Conforme Oliveira et al. (1992), a avaliação deve ser um dos elementos principais para o estabelecimento e acompanhamento de uma política nacional de ensino e pesquisa, ao passo que permite um diagnóstico das potencialidades das instituições acadêmicas.

Como um dos principais instrumentos de divulgação da área contábil-financeira a Revista de Contabilidade \& Finanças - USP apresenta-se como uma notória forma de avaliação do processo de produção científica. Para ressaltar a notoriedade desse periódico, observa-se sua consolidação nos 20 anos de existência. É classificada como B1 no estrato de periódicos do Qualis CAPES (Coordenação de Aperfeiçoamento de Pessoal de Nível Superior), destacando a sua relevância no meio contábil, tanto pelo nível dos trabalhos publicados, como também pela própria qualidade de apresentação do periódico.

As evidências mostram que os resultados de avaliação de periódicos na área das Ciências Contábeis e Finanças, contribuem para a consolidação, explicação, discussão e reflexão sobre o caráter de cientificidade da área, fazendo com que os seus resultados se acrescentem aos trabalhos anteriores. Além, desses fatores, como dispõe Leite Filho (2008), é importante ressaltar os impactos e os benefícios gerados, pois se permite nesse caso, que se 
verifique o fluxo documentado e a evolução da pesquisa ao longo do tempo e pode servir, portanto, como fonte para se avaliar ou medir os efeitos de uma pesquisa em particular, de um grupo ou instituição de pesquisadores, ou ainda de veículos de divulgação científica.

Diante do exposto, verifica-se a importância da produção científica decorrente dos trabalhos publicados nos periódicos nacionais. Neste intuito, surge a seguinte questão: Qual o perfil e as tendências das publicações da Revista de Contabilidade \& Finanças - USP no período de 1989 a 2009? O estudo pretende identificar e descrever o desenvolvimento do periódico Contabilidade \& Finanças - USP como importante meio de divulgação do conhecimento científico em Ciências Contábeis e Finanças, além de demonstrar as aplicações relacionadas às metodologias de pesquisa evidenciadas nestes trabalhos acadêmicos.

Segundo Schwartzman (1984), é relevante indagar as publicações científicas e técnicas, pois quando são feitas em revistas de boa qualidade, dotadas de sistemas adequados de avaliação e crítica de manuscritos, desempenham ainda duas funções primordiais, ainda que pouco evidentes à primeira vista. Primeiro, elas têm um importante papel pedagógico junto ao pesquisador, que é levado a expor o resultado de sua pesquisa a outros especialistas em seu campo, recebendo sugestões, críticas e comentários que podem ser decisivos para aperfeiçoar e mesmo reorientar os trabalhos. Segundo, os corpos editoriais das revistas funcionam como um mecanismo altamente qualificado de avaliação final da pesquisa.

\section{REVISÃO DA LITERATURA}

\subsection{A Pesquisa Científica na Contabilidade}

Segundo Marconi e Lakatos (2001), o conhecimento científico visa explicar porque e como os fenômenos ocorrem na tentativa de evidenciar os fatos que estão correlacionados, em uma visão globalizante. Essa é uma percepção que se torna clara ao analisar-se a evolução do saber científico e ao observar-se que é decorrente de um agregado de estudos, descobertas e análises que vão se acumulando através do tempo e que formam um arcabouço conceitual sobre cada um dos vários conhecimentos classificados como Ciência.

Silva (2003) destaca que a Ciência não corresponde a um mundo a descrever, corresponde a um mundo a construir. Essa construção é caracterizada como fruto do trabalho desenvolvido por estudiosos, pesquisadores, professores, alunos, ou seja, por todo um conjunto de pessoas que tem interesse comum em explicar os fenômenos que acontecem ao seu redor e que estão compreendidos dentro dos seus objetos de estudo.

Duarte et al. (2007) mostram que a produção científica quadruplica a cada década, decorrente principalmente da ampliação e pelo avanço das tecnologias de informação e de comunicação. Considerando que a ciência possui caráter evolutivo e mutável, a pesquisa científica torna-se seu instrumento básico.

Nessa direção, no âmbito da Contabilidade, Silva, Oliveira e Ribeiro Filho (2005) mencionam que a pesquisa científica vem sendo fortalecida dia-a-dia com empenho de pesquisadores, professores e estudantes que buscam analisar os fenômenos que ocorrem no contexto da Ciência Contábil. Ainda conforme os autores, as pesquisas da área contábil em sua maioria são apresentadas em encontros, congressos, periódicos e, sobretudo, nos cursos de pós-graduação lato sensu e stricto sensu, viabilizando a difusão do conhecimento.

De acordo a Silva et al. (2004), os cursos de pós-graduação lato sensu, em geral, exigem ao seu término a elaboração de um artigo ou monografia. Os cursos de mestrado e doutorado exigem apresentação de dissertação, ensaio ou defesa de tese. Todo esse material produzido acrescenta à Contabilidade uma exposição em caráter de pesquisa científica sobre temas diversos, aumentando, assim, a divulgação do conhecimento e difundindo a Ciência Contábil como ramo do conhecimento que busca prover seus usuários de informações úteis, tempestivas e auxiliares do processo decisório, em qualquer esfera empresarial. 
Para Oliveira (2002), essa produção é mais bem contextualizada nas regiões onde estão concentrados os cursos de pós-graduação em Contabilidade, visto que um dos focos principais desses cursos é a preparação dos alunos para o exercício da docência e para a realização de pesquisas científicas. Ainda segundo a autora, os conteúdos abordados nos artigos são de grande interesse para a comunidade contábil e também tratam de temas escassos na literatura nacional, destacando, desse modo, a importância das pesquisas.

Atualmente, sob a perspectiva de aspectos qualitativos, os estudos de Contabilidade segundo Silva, Oliveira e Ribeiro Filho (2005) estão inseridos em uma preocupação quanto à qualidade destes trabalhos, principalmente quando publicados em periódicos. Para Krzyzanowski e Ferreira (1998), tem-se uma preocupação quanto à publicação de revistas sem critérios de qualidade e com as quais vêm se perdendo esforços, material publicado, recursos financeiros e até prestigio de organizações científicas ou instituições.

Para Oliveira (2002), os artigos publicados em periódicos representam uma relevante parte do fluxo de informação originado com a atividade científica da pesquisa. São trabalhos que obedecem a rigores científicos e assim sendo são divulgados em periódicos, congressos, eventos que buscam evidenciar estudos de qualidade e que versem sobre temas que sejam úteis a toda classe interessada.

Em pesquisa realizada por Oliveira (2002), com uma análise feita sobre os periódicos brasileiros de Contabilidade, destacou alguns aspectos importantes: a) a maioria dos autores são docentes, o que evidencia que grande parte das pesquisas em Contabilidade são originárias das universidades; b) muitos autores são pós-graduados, caracterizando a importância dos periódicos como meio de divulgação para a comunidade científica nacional; c) os temas mais privilegiados com trabalhos são Contabilidade Gerencial, Contabilidade Financeira, Teoria da Contabilidade, Educação e Pesquisa Contábil e Contabilidade de Custos, fato que demonstra a importância da Contabilidade Gerencial nessas pesquisas.

Porém, a preocupação em relação aos periódicos e aos trabalhos neles divulgados quanto à qualidade continua crescente. Atualmente vem sendo publicadas pesquisas que tem o intuito de demonstrar os elementos qualitativos da publicação. Como dispõem Borba e Murcia (2006), as pesquisas cujo enfoque é investigar as tendências e traçar o perfil de uma determinada área, em uma determinada época, têm ganhado força nos últimos anos, principalmente com a publicação de diversos trabalhos a respeito do assunto em vários meios de comunicação científica. Traçar o perfil de pesquisadores ou de uma determinada área, em uma determinada época, sob determinada perspectiva, reflete o comportamento de uma ordem, visando conhecer seus trajetos e fazer projeções de futuras tendências de estudos.

Mendonça Neto et al. (2004) afirmam que este tipo de pesquisa torna-se importante para o desenvolvimento da Ciência. A produção na área contábil representa baixo percentual em relação à produção internacional e é através dessa investigação e tendências de pesquisas que se pode elencar necessidades da comunidade acadêmica e anseios da sociedade.

Diversos são os trabalhos que buscam a investigação da pesquisa científica. Zeff (1996) pesquisou em revistas norte-americanas na área de Contabilidade padrões de autoria, cientificidade e a continuidade dos periódicos. Como principais resultados aponta que a área possui forte endogenia e que há concentração em autores e instituições acadêmicas.

Willians e Rodgers (1996) pesquisaram os padrões de pesquisa, produtividade de autores e criação de novos conhecimentos no periódico norte-americano The Accounting Review (TAR), no período de 1967 a 1993. Os principais resultados indicaram que houve uma estratificação em publicações em outras áreas do conhecimento e que havia uma forte correlação com um agrupamento de universidades de elites, sendo que autores com maior produtividade no TAR estariam de alguma forma ligados a estas instituições. Observaram também que esta elite de autores que produz artigos na área de contabilidade cresceu em outras áreas das ciências sociais, especialmente em economia e psicologia cognitiva. 
Fogarty (2004) pesquisou a produção do conhecimento de recém doutores norteamericanos na área de Ciências Contábeis, egressos desde 1977. O estudo revelou indícios de que a manutenção da produtividade dos autores estava associada ao status institucional outorgado pela universidade. Além disso, a continuidade nas publicações poderia ser explicada por fatores institucionais e pessoais. Quanto aos fatores pessoais, autores que têm publicado mais em suas carreiras tendem a permanecer mais tempo nas atividades escolares, principalmente quando há incentivos, como participação em congressos e encontros de pesquisa. $\mathrm{O}$ autor assevera que isto pode ser interpretado como uma diferença motivacional.

Cardoso et al. (2005) avaliaram a distribuição, características metodológicas e a evolução temática das publicações e produção dos autores brasileiros de textos em Contabilidade em revistas de Administração e Economia de 1990 a 2003. Os principais resultados demonstraram que pode ser considerada baixa $(2,95 \%)$ a concentração de pesquisa publicada em poucos autores com grande número de artigos publicados. Comparando com outros trabalhos internacionais e nacionais, os autores classificaram a produtividade dos autores brasileiros em Contabilidade como baixa.

Leal et al. (2003) realizaram pesquisa bibliométrica em 551 artigos na área de finanças, publicados entre 1974 e 2001 em periódicos nacionais de administração e economia. Os resultados mostraram que a maioria dos artigos apresentou somente um autor, a produtividade dos autores é concentrada e difere dos padrões das leis bibliométricas.

Santana (2004) investigou a pesquisa em contabilidade social no Brasil de 1990 a 2003 utilizando análise bibliométrica. Como resultados principais o autor encontrou indícios de concentração de artigos nos últimos sete anos pesquisados $(89 \%)$ e na temática de Balanço Social $(45 \%)$. Observou ainda que a produção é pequena no que diz respeito a periódicos avaliados pelo Qualis CAPES (11,8\% do total). Verificou ainda uma concentração de artigos em poucos autores, além de evidências de endogenia na área de Contabilidade Social.

\subsection{Metodologia, Método e Técnica}

Segundo Bruyne (1991), a metodologia deve ajudar a explicar não apenas os produtos da investigação científica, mas principalmente seu próprio processo. Por isso os princípios metodológicos não podem ser redutíveis à tecnologia e a um design. Mas a complexidade das problemáticas em ciências sociais exige interpretações e voltas constantes entre os pólos epistemológico, teórico, morfológico, e técnico de pesquisa.

Metodologia é definida por Demo (1995) como o estudo dos caminhos, dos instrumentos usados para se fazer ciência. É uma disciplina instrumental a serviço da pesquisa. Ao mesmo tempo que visa conhecer caminhos do processo científico, também problematiza criticamente, no sentido de indagar os limites da ciência, seja com referência à capacidade de conhecer, seja com referência à capacidade de intervir na realidade.

Asti Vera (1983) aduz que metodologia tem dois significados: o primeiro, que é uma disciplina chamada metodologia e, o segundo, que é o estudo analítico e crítico dos métodos de investigação e de prova. O autor determina metodologia como sendo a descrição, análise e avaliação crítica dos métodos de investigação.

Barros e Lehfeld (2000) entendem metodologia como uma disciplina que se relaciona com a epistemologia. Consiste em estudar e avaliar os vários métodos disponíveis, identificando suas limitações ou não em nível das implicações de suas utilizações, corresponde a um conjunto de procedimentos a serem utilizados na obtenção do conhecimento. É a aplicação do método através de processos e técnicas que garantem a legitimidade do saber obtido.

Dessa forma, a metodologia consiste em definir onde e como será realizada a pesquisa. Implica na escolha de estratégias para conduzir os trabalhos de investigação. A definição do método a ser empregado, participa do processo da metodologia, que escolhe em um conjunto 
de procedimentos disponíveis, o melhor a ser utilizado.

Além da discussão sobre os conceitos de metodologia, vale ressaltar a relação entre metodologia, método e técnica. Para Demo (1995), metodologia distingue-se de método e técnica, pois considera que os dois últimos tratam da realidade empírica, enquanto a metodologia prende-se mais às discussões problematizantes. Com isso, a metodologia situa-se no nível da discussão teórica, discutindo criticamente sobre as maneiras de se fazer a ciência. Por outro lado, Asti Vera (1983) diferencia método e técnica por uma diferença semântica análoga à que distingue o gênero da espécie.

No intuito de demonstrar a distinção entre os conceitos, seguem-se as definições. Método, segundo Barros e Lehfeld (2000), consiste na forma ordenada de proceder ao longo de um caminho, um conjunto de processos ou fases empregadas na investigação, na busca do conhecimento, é em geral "o que fazer". Por exemplo, os métodos de pesquisa. Técnicas são procedimentos que operacionalizam os métodos, mediante emprego de instrumentos adequados (SEVERINO, 1996). É em geral “como fazer”. Por exemplo, a análise de conteúdo (BARDIN, 1977) e os instrumentos são os meios utilizados na coleta dos dados. Como exemplo, questionários, formulários, entrevistas etc.

Em suma, o método é a fase inicial da pesquisa. Primeiro é necessário traçar as estratégias da pesquisa para depois partir para a execução. Essa etapa, da operacionalização do método, será concretizada pelo emprego da técnica, com o auxilio de instrumentos.

\section{METODOLOGIA}

\subsection{Tipo de Pesquisa}

Para Gil (1996), em relação aos objetivos gerais, é possível classificar as pesquisas em três grupos: exploratórias, descritivas e explicativas. Para Malhotra (2001), a pesquisa exploratória é usada nos casos em que é necessário definir o problema com maior precisão, identificar cursos relevantes de ação ou obter dados adicionais antes que se possa desenvolver uma abordagem. Pesquisa descritiva, para Martins (1994), é aquela que objetiva a descrição das características de determinada população ou fenômeno, bem como o estabelecimento de relação entre variáveis e fatos. Na visão de Andrade (2002), a pesquisa explicativa é mais complexa, pois, além de registrar, analisar, classificar e interpretar os fenômenos estudados procura identificar seus fatores determinantes.

Com base na classificação apresentada, essa proposta de pesquisa caracteriza-se como descritiva, pois se pretende identificar e descrever o desenvolvimento do periódico Contabilidade \& Finanças - USP como importante meio de divulgação do conhecimento científico em Ciências Contábeis e demonstrar as aplicações relacionadas às metodologias de pesquisa evidenciadas nestes trabalhos acadêmicos. Quanto aos meios esta pesquisa é bibliográfica e documental, e utiliza-se da técnica de análise de conteúdo. Desta forma, apresenta-se predominantemente qualitativa, porém com o auxílio de técnicas quantitativas utilizadas na adequação numérica dos artigos.

\subsection{Delimitação e Operacionalização do Estudo}

Para o desenvolvimento deste estudo delimitou-se como objeto de análise a Revista Contabilidade \& Finanças da Universidade de São Paulo. No intuito de evidenciar a notoriedade deste periódico, coloca-se que tem 20 anos de existência, sendo sua primeira edição publicada sob a denominação de Caderno de Estudos em 1989.

Inicialmente surgiu exclusivamente para a publicação de estudos voltados aos professores e alunos da USP, porém a partir de 2001 com a alteração para o nome atual vigente, passou a apresentar um conteúdo mais diversificado de autores, ressaltando assuntos 
sobre Contabilidade. Atualmente, a Revista tem edição quadrimestral e é publicada pelo Departamento de Contabilidade e Atuária da FEA/USP. O periódico é considerado pela Coordenação de Aperfeiçoamento de Pessoal de Nível Superior (CAPES) como B1.

Assim, este estudo abrangeu como período de análise os 20 anos da revista. Para tanto consideraram-se 354 artigos, distinguidos em nacionais e internacionais, sendo que foram pesquisadas as dimensões relativas ao número de páginas e fascículos, número de autores por artigo, filiação acadêmica, titulação acadêmica, autores mais representativos, referências utilizadas, instituições, temática produzida e metodologia aplicada. Há de se destacar que, para o levantamento da temática produzida e metodologia aplicada utilizou-se como conceitos os trabalhos apresentados por Martins (2002) e Silva, Oliveira e Ribeiro Filho (2005). Além disso, acrescentaram-se algumas temáticas e metodologias pertinentes ao estudo.

\section{RESULTADOS E DISCUSSÕES}

\subsection{Publicações da Revista Contabilidade \& Finanças - USP}

Inicialmente, o advento da Revista Contabilidade \& Finanças - USP, sob a denominação de Cadernos de Estudos, apresentava-se com características meramente institucionais, no intuito de desenvolver publicações, principalmente didáticas, de professores e alunos da pós-graduação da Universidade de São Paulo. Nos primeiros anos de publicação, restringia-se a poucos trabalhos e de dimensões reduzidas. Além disso, não possuía uma periodicidade constante, variando até 2001 entre 1 a 3 fascículos anuais. A partir do referido ano houve a definição de publicações quadrimestrais, porém, ressalta-se que em alguns períodos se apresentaram edições suplementares devido a datas comemorativas e especiais.

Quanto ao número de artigos por fascículo, as publicações apresentaram grande variabilidade. Até 2001, considerado como marco da própria Revista de Contabilidade \& Finanças - USP, em média havia 4 artigos por fascículos, sendo que o número de páginas variou entre 28 a 308. A partir de 2001, com a definição de publicações quadrimestrais, o periódico passou a apresentar oito artigos por fascículo, em média. Entretanto, a variação entre a quantidade de páginas publicadas continuou a mesma com proporções elevadas, demonstrando-se entre 253 e 633 páginas (Tabela 1).

Tabela 1 - Distribuição dos fascículos e artigos

\begin{tabular}{lccccccc}
\hline Anos & $\mathbf{1 9 8 9}$ & $\mathbf{1 9 9 0}$ & $\mathbf{1 9 9 1}$ & $\mathbf{1 9 9 2}$ & $\mathbf{1 9 9 3}$ & $\mathbf{1 9 9 4}$ & $\mathbf{1 9 9 5}$ \\
\hline Número de Fascículos & 1 & 1 & 1 & 3 & 2 & 2 & 1 \\
Número de Artigos & 4 & 4 & 4 & 13 & 9 & 8 & 4 \\
Número de Páginas Anuais & 28 & 53 & 43 & 272 & 125 & 113 & 48 \\
Médias de Páginas por Artigo & 7.00 & 13.25 & 10.75 & 20.92 & 13.89 & 14.13 & 12.00 \\
\hline Anos & $\mathbf{1 9 9 6}$ & $\mathbf{1 9 9 7}$ & $\mathbf{1 9 9 8}$ & $\mathbf{1 9 9 9}$ & $\mathbf{2 0 0 0}$ & $\mathbf{2 0 0 1}$ & $\mathbf{2 0 0 2}$ \\
\hline Número de Fascículos & 2 & 2 & 3 & 3 & 2 & 3 & 3 \\
Número de Artigos & 7 & 11 & 19 & 14 & 8 & 17 & 18 \\
Número de Páginas Anuais & 144 & 165 & 291 & 235 & 133 & 308 & 255 \\
Médias de Páginas por Artigo & 20.57 & 15.00 & 15.32 & 16.79 & 16.63 & 18.12 & 14.17 \\
\hline Anos & $\mathbf{2 0 0 3}$ & $\mathbf{2 0 0 4}$ & $\mathbf{2 0 0 5}$ & $\mathbf{2 0 0 6}$ & $\mathbf{2 0 0 7}$ & $\mathbf{2 0 0 8}$ & $\mathbf{D e z - 0 9}$ \\
\hline Número de Fascículos & 4 & 4 & 3 & 5 & 4 & 3 & 3 \\
Número de Artigos & 32 & 31 & 25 & 45 & 33 & 26 & 22 \\
Número de Páginas anuais & 525 & 339 & 339 & 633 & 412 & 372 & 380 \\
Médias de Páginas por Artigo & 16.41 & 10.94 & 13.56 & 14.07 & 12.48 & 14.31 & 17.27 \\
\hline Fonte: dad da pesquisa & & & & & & & \\
\hline
\end{tabular}

Fonte: dados da pesquisa

Desde o início da publicação do periódico até o ano de 1995 observa-se a 
predominância de publicações com somente um autor, respondendo a aproximadamente $77 \%$. No período posterior, considerando 1996 a 2002, a preponderância continua em um autor (66\%), porém a representatividade na quantidade de maior número de autores eleva-se com o avanço dos anos da revista. Entre 2003 e 2009, apresentam-se trabalhos com até 6 autores, e na maioria os artigos demonstram-se com 2 e 3 autores $(71 \%)$ e a representatividade de publicações com único autor, reduziu-se a 17,8\% (Tabela 2).

Tabela 2 - Número máximo de autores por artigo

\begin{tabular}{lccccccc}
\hline Autoria / Anos & $\mathbf{1 9 8 9}$ & $\mathbf{1 9 9 0}$ & $\mathbf{1 9 9 1}$ & $\mathbf{1 9 9 2}$ & $\mathbf{1 9 9 3}$ & $\mathbf{1 9 9 4}$ & $\mathbf{1 9 9 5}$ \\
\hline Máximo um autor & 3 & 2 & 4 & 12 & 4 & 5 & 4 \\
Máximo dois autores & 1 & - & - & 1 & 2 & 1 & - \\
Máximo três autores & - & - & - & - & 3 & - & - \\
Máximo quatro autores & - & 2 & - & - & - & - & - \\
Máximo cinco autores & - & - & - & - & - & - & - \\
Máximo seis autores & - & - & - & - & - & - & - \\
\hline Autoria / Anos & $\mathbf{1 9 9 6}$ & $\mathbf{1 9 9 7}$ & $\mathbf{1 9 9 8}$ & $\mathbf{1 9 9 9}$ & $\mathbf{2 0 0 0}$ & $\mathbf{2 0 0 1}$ & $\mathbf{2 0 0 2}$ \\
\hline Máximo um autor & 6 & 9 & 16 & 9 & 7 & 3 & 12 \\
Máximo dois autores & 1 & 1 & 3 & 4 & - & 12 & 5 \\
Máximo três autores & - & 1 & - & 1 & 1 & 1 & 1 \\
Máximo quatro autores & - & - & - & - & - & 1 & - \\
Máximo cinco autores & - & - & - & - & - & - & - \\
Máximo seis autores & - & - & - & - & - & - & - \\
\hline Autoria / Anos & $\mathbf{2 0 0 3}$ & $\mathbf{2 0 0 4}$ & $\mathbf{2 0 0 5}$ & $\mathbf{2 0 0 6}$ & $\mathbf{2 0 0 7}$ & $\mathbf{2 0 0 8}$ & $\mathbf{D e z}-\mathbf{2 0 0 9}$ \\
\hline Máximo um autor & 12 & 5 & 4 & 8 & 4 & 3 & 2 \\
Máximo dois autores & 14 & 17 & 10 & 21 & 12 & 14 & 11 \\
Máximo três autores & 6 & 6 & 9 & 12 & 9 & 5 & 6 \\
Máximo quatro autores & - & 3 & 1 & 1 & 7 & 2 & 1 \\
Máximo cinco autores & - & - & 1 & 3 & - & 2 & 2 \\
Máximo seis autores & - & - & - & - & 1 & & - \\
\hline Font: dados da pesquisa & & & & & & \\
\hline
\end{tabular}

Fonte: dados da pesquisa.

Conforme já descrito, a Revista Contabilidade \& Finanças inicialmente apresentava endogenia nas publicações de professores e alunos da pós-graduação da USP. Para corroborar a afirmação anterior, verifica-se que no período entre 1989 e 1995 as publicações concentraram-se basicamente em docentes e discentes afiliados a USP (90\%). Destes, 50\% eram professores, 36\% alunos de mestrado e doutorado e 4\% alunos de graduação. De 1996 a 2002, a representatividade de publicações de afiliados a USP era absoluta (60\%), porém a participação de outras entidades tornou-se significativa, passando de $10 \%$ para $40 \%$, principalmente com a participação de professores nas publicações, respondendo a $26 \%$.

Essas constatações neste período de análise do periódico corroboram as conclusões observadas por Martins (2002) e Silva, Oliveira e Ribeiro Filho (2005), ao analisarem a Revista de Contabilidade \& Finanças - USP entre 1989 a 2004. Além disso, os resultados acima descritos encontram simetria nos estudos de Chung et al. (1992), Zeff (1996), Willians e Rodgers (1996), Bino et al. (2002), Leal et al. (2003), Moriki e Martins (2003), Santana (2004), Cardoso et al. (2005), nos quais os autores também observaram indícios de endogenia em veículos de publicação, concentração de autores e instituições e monopólio de instituições na autoria e produção acadêmica de Contabilidade e Finanças.

A concentração de autoria verificada em poucas instituições nacionais e a endogenia podem estar relacionadas ao baixo número de programas de pós-graduação stricto sensu nas áreas de Contabilidade e Finanças no Brasil, pois as instituições (principalmente a USP), em que foram observadas as mais altas frequiências relativas de autoria no periódico, são as que 
mantêm estes programas de pós-graduação. Segundo Leite Filho (2008), estas instituições tem incentivado professores, alunos e pesquisadores a publicar e apresentar trabalhos em periódicos e congressos com critérios de qualidade avaliados pela CAPES, o que também é um dos requisitos para se avaliar e manter os conceitos dos referidos programas.

No período de 2003 a 2009 percebe-se uma mudança de contexto das publicações do periódico. A participação de outras entidades demonstra-se notória, perfazendo aproximadamente $73 \%$, neste evidencia-se a crescente contribuição de docentes e, principalmente a elevação de artigos publicados por alunos de outros programas de pósgraduação. Lucena, Cavalcante e Sales (2007) também apontam que, os cursos de graduação, apesar de ainda pouco representativos, têm sua importância na pesquisa científica, uma vez que estes formam a base do futuro pesquisador.

O crescimento da publicação de outras entidades demonstra a importância do conceito que a revista adquiriu. Vale ressaltar as principais instituições responsáveis pela participação na publicação do periódico. Os autores predominantes nos 20 anos de existência deste instrumento científico estavam afiliados a USP (276 autores), porém neste período observa-se a representatividade do número de autores de outras organizações, sendo que se destacam principalmente aquelas que desenvolvem a pesquisa em Contabilidade no nível de graduação e pós-graduação, ilustra-se, a Pontifícia Universidade Católica - PUC (33 autores), a Fundação Instituto Capixaba de Pesquisa em Contabilidade, Economia e Finanças - FUCAPE/ES (25 autores), a Universidade Federal do Rio de Janeiro - UFRJ/RJ (21 autores) e a Universidade Federal do Ceará - UFC/CE (22 autores) (Tabelas 3 e 4)

Tabela 3 - Filiação acadêmica dos autores

\begin{tabular}{|c|c|c|c|c|c|c|c|}
\hline Filiação Acadêmica / Ano & 1989 & 1990 & 1991 & 1992 & 1993 & 1994 & 1995 \\
\hline Professores USP & 4 & 2 & 2 & 10 & 12 & 1 & 1 \\
\hline Alunos Pós-Graduação USP & 1 & 8 & - & - & 4 & 7 & 3 \\
\hline Alunos Graduação USP & - & - & - & 2 & - & - & - \\
\hline Professores Outras Entidades & - & - & 1 & 1 & 2 & - & - \\
\hline Alunos de Pós-Graduação Outras Entidades & - & - & - & 2 & - & - & - \\
\hline Alunos de Graduação Outras Entidades & - & - & - & - & - & - & - \\
\hline Universidades Estrangeiras & - & - & - & - & - & - & - \\
\hline Sem Vínculo Acadêmico & - & - & 1 & - & - & - & - \\
\hline Filiação Acadêmica / Ano & 1996 & 1997 & 1998 & 1999 & 2000 & 2001 & 2002 \\
\hline Professores USP & 4 & 5 & 3 & 9 & 5 & 6 & 9 \\
\hline Alunos Pós-Graduação USP & 1 & 7 & 8 & 4 & 1 & 7 & 5 \\
\hline Alunos Graduação USP & - & - & - & 2 & - & 1 & 1 \\
\hline Professores Outras Entidades & 2 & 2 & 9 & 2 & 3 & 9 & 6 \\
\hline Alunos de Pós-Graduação Outras Entidades & - & - & - & 1 & - & 1 & 1 \\
\hline Alunos de Graduação Outras Entidades & - & - & - & - & - & 4 & - \\
\hline Universidades Estrangeiras & - & - & 1 & 1 & - & 4 & 3 \\
\hline Sem Vínculo Acadêmico & - & - & 2 & - & - & 1 & - \\
\hline Filiação Acadêmica / Ano & 2003 & 2004 & 2005 & 2006 & 2007 & 2008 & Dez - 2009 \\
\hline Professores USP & 19 & 15 & 11 & 19 & 14 & 12 & 14 \\
\hline Alunos Pós-Graduação USP & 8 & 8 & 2 & 5 & 6 & 3 & 2 \\
\hline Alunos Graduação USP & - & - & - & - & - & - & - \\
\hline Professores Outras Entidades & 26 & 27 & 29 & 53 & 47 & 39 & 31 \\
\hline Alunos de Pós-Graduação Outras Entidades & 4 & 3 & 11 & 12 & 14 & 8 & 3 \\
\hline Alunos de Graduação Outras Entidades & - & 1 & 1 & 3 & 1 & 1 & 1 \\
\hline Universidades Estrangeiras & 10 & 5 & 6 & 12 & 6 & 3 & 4 \\
\hline Sem Vínculo Acadêmico & 1 & 1 & 1 & 1 & - & - & 3 \\
\hline
\end{tabular}

Fonte: dados da pesquisa. 
Tabela 4 - Número de autores representativos quanto a Instituição e publicação

\begin{tabular}{lc}
\hline Instituição & Autores \\
\hline Universidade de São Paulo - USP/SP & 276 \\
Pontifícia Universidade Católica - PUC/SP/RJ/MG/RS/PR & 33 \\
Fundação Instituto Capixaba de Pesquisa em Contabilidade, Economia e Finanças - FUCAPE/ES & 25 \\
Universidade Federal do Rio de Janeiro - UFRJ/RJ & 21 \\
Universidade Federal do Ceará - UFC/CE & 22 \\
Universidade de Brasília - UNB/DF & 19 \\
Universidade Presbiteriana Mackenzie - Mackenzie/SP & 18 \\
Universidade Federal de Santa Catarina - UFSC/SC & 16 \\
\hline
\end{tabular}

Fonte: dados da pesquisa.

Outro aspecto relevante analisado, quanto às publicações da revista, refere-se à titulação dos autores. Nesta distinção é possível observar o incentivo ao trabalho científico nos diferentes níveis do conhecimento acadêmico. O periódico analisado apresenta diversos títulos relacionados aos autores, desde alunos de graduação a pós-doutores (Tabela 5).

Tabela 5 - Titulação dos autores

\begin{tabular}{|c|c|c|c|c|c|c|c|}
\hline Titulação autoral / Ano & 1989 & 1990 & 1991 & 1992 & 1993 & 1994 & 1995 \\
\hline Especialista & - & - & - & - & - & - & - \\
\hline Pós-Doutor & - & - & - & - & - & - & - \\
\hline Professor & 3 & 2 & 3 & 11 & 13 & 1 & 1 \\
\hline Doutor & - & - & - & - & - & 1 & - \\
\hline Mestre & - & - & - & - & 1 & 1 & 2 \\
\hline Graduação & - & - & - & - & - & - & - \\
\hline Mestrando & 1 & 4 & - & 2 & - & - & - \\
\hline Doutorando & - & 4 & - & 2 & - & 5 & 1 \\
\hline Titulação autoral / Ano & 1996 & 1997 & 1998 & 1999 & 2000 & 2001 & 2002 \\
\hline Especialista & - & - & - & - & - & - & - \\
\hline Pós-Doutor & - & - & - & - & - & 1 & - \\
\hline Professor & 6 & 7 & 13 & 13 & 9 & 19 & 18 \\
\hline Doutor & 1 & - & 1 & - & - & 2 & - \\
\hline Mestre & - & - & - & - & - & 1 & 2 \\
\hline Graduação & - & - & - & 3 & - & 5 & 1 \\
\hline Mestrando & - & 6 & 6 & 2 & 1 & 2 & 2 \\
\hline Doutorando & - & 1 & 1 & 3 & - & 3 & 2 \\
\hline Titulação autoral / Ano & 2003 & 2004 & 2005 & 2006 & 2007 & 2008 & Dez - 2009 \\
\hline Especialista & 1 & - & - & - & 1 & - & - \\
\hline Pós-Doutor & - & - & - & - & - & - & - \\
\hline Professor & 55 & 48 & 45 & 81 & 65 & 54 & 47 \\
\hline Doutor & - & - & - & 2 & - & - & - \\
\hline Mestre & 2 & 1 & 6 & 5 & 6 & 5 & 2 \\
\hline Graduação & - & 1 & 1 & 3 & 1 & 1 & 1 \\
\hline Mestrando & 7 & 5 & 5 & 5 & 6 & 3 & 2 \\
\hline Doutorando & 2 & 5 & 2 & 7 & 7 & 3 & 1 \\
\hline
\end{tabular}

Fonte: dados da pesquisa.

Verifica-se que as publicações quanto à titulação estão concentradas nos professores. No período de 1989 a 1995, dos trabalhos publicados, 58\% eram docentes, destes o grau de formação eram variados, sendo que $71 \%$ eram doutores e $14 \%$ doutorandos. A maioria representava filiação a USP e seus programas de pós-graduação. Observa -se a endogenia de publicações de autores relacionados ao stricto sensu, já que os trabalhos no periódico 
abrangiam doutorandos e doutores (23\%); mestres e mestrandos (19\%).

No período entre 1996 a 2002 verifica-se a predominância na publicação de professores (65\%), na maioria doutores (55\%), mestrandos $(13 \%)$ e doutorandos (14\%). Entretanto, observa-se a participação de alunos de graduação e graduados na publicação, que ainda é incipiente, respondendo por $7 \%$, o que pode demonstrar um início no incentivo ao discente nos trabalhos acadêmicos. Um dos elementos determinantes à inserção deste nível de conhecimento está nas bolsas de iniciação científica (IC). Segundo o Conselho Nacional de Desenvolvimento Científico e Tecnológico (CNPq), a IC é um instrumento que permite introduzir na pesquisa científica os estudantes de graduação. Esta se refere a uma ferramenta teórica e metodológica à realização de um projeto de pesquisa e constitui um canal adequado de auxílio para a formação de uma nova mentalidade no aluno.

Nos anos de 2003 a 2009, a representatividade da produção acadêmica dos professores é preponderante $(80 \%)$. Da mesma forma as análises anteriores, em sua maioria os docentes são doutores (59\%), porém distintamente observa-se como titulação também participativa os mestres (14\%), enquanto mestrandos e doutorandos respondem por apenas $4 \%$. No que tange aos outros autores, percebe-se a notória contribuição dos alunos de pós-graduação na publicação, destes doutorandos perfazem 5,3\% dos trabalhos, enquanto mestrandos 6,7\%. Nessa direção, destaca-se a importância dos programas stricto sensu na colaboração do desenvolvimento científico, pois como coloca Oliveira (2002), a produção científica é mais bem contextualizada nas regiões onde estão concentrados os cursos de pós-graduação em Contabilidade, visto que um dos focos principais desses cursos é a preparação dos alunos para o exercício da docência e para a realização de pesquisas científicas (Tabelas 5 e 6).

É importante ressaltar que, devido ao estudo considerar a questão temporal da revista, alguns autores podem ter alterado sua titulação e vinculação. Logo alguns autores podem não ser mais docentes de determinadas instituições, ou agora são mestres ou doutores, dentre outras possibilidades.

Tabela 6 - Titulação dos professores autores

\begin{tabular}{lccccccc}
\hline Titulação Professor / Ano & $\mathbf{1 9 8 9}$ & $\mathbf{1 9 9 0}$ & $\mathbf{1 9 9 1}$ & $\mathbf{1 9 9 2}$ & $\mathbf{1 9 9 3}$ & $\mathbf{1 9 9 4}$ & $\mathbf{1 9 9 5}$ \\
\hline Sem definição de título & 3 & - & - & 1 & - & - & - \\
Mestre & - & - & - & - & - & - & - \\
Doutor & - & 2 & 3 & 6 & 7 & 1 & 1 \\
Graduado & - & - & - & - & - & - & - \\
Mestrando & - & - & - & - & - & - & - \\
Doutorando & - & - & - & 2 & 2 & - & - \\
\hline Titulação Professor / Ano & $\mathbf{1 9 9 6}$ & $\mathbf{1 9 9 7}$ & $\mathbf{1 9 9 8}$ & $\mathbf{1 9 9 9}$ & $\mathbf{2 0 0 0}$ & $\mathbf{2 0 0 1}$ & $\mathbf{2 0 0 2}$ \\
\hline Sem definição de título & - & - & - & - & - & 2 & 4 \\
Mestre & 1 & - & - & 1 & 2 & 3 & 1 \\
Doutor & 5 & 1 & 4 & 10 & 5 & 9 & 12 \\
Graduado & - & - & - & - & - & - & - \\
Mestrando & - & - & 7 & - & 1 & 2 & 1 \\
Doutorando & - & 6 & 2 & 2 & 1 & 1 & - \\
\hline Titulação Professor / Ano & $\mathbf{2 0 0 3}$ & $\mathbf{2 0 0 4}$ & $\mathbf{2 0 0 5}$ & $\mathbf{2 0 0 6}$ & $\mathbf{2 0 0 7}$ & $\mathbf{2 0 0 8}$ & Dez - 2009 \\
\hline Sem definição de título & 14 & 11 & 6 & 19 & 13 & 9 & 12 \\
Mestre & 6 & 5 & 6 & 13 & 10 & 9 & 7 \\
Doutor & 32 & 31 & 28 & 41 & 41 & 31 & 23 \\
Graduado & - & - & - & - & 1 & - & 1 \\
Mestrando & - & - & - & 4 & - & - & - \\
Doutorando & -1 & 3 & - & 2 & 2 \\
\hline Fone: dados da pesquisa & - & - & & & \\
\hline
\end{tabular}

Fonte: dados da pesquisa. 
Considerando a disposição dos autores quanto à titulação, vale evidenciar a representatividade quanto à quantidade publicada de trabalhos no periódico. Neste sentido, elencam-se os principais autores, que de certa forma, contribuíram para o desenvolvimento da Revista. De acordo com a análise dos artigos, verifica-se que dentre os autores levantados como principais publicadores do periódico, a maioria se constitui de professores e afiliados a Universidade de São Paulo. Ressalta-se, primordialmente, que os textos oriundos destes respectivos autores, tratam-se predominantemente de assertivas didáticas, ou trabalhos decorrentes da orientação de recortes de dissertações e teses de doutorado.

Um fato a ser considerado, refere-se a autores que de certa forma contribuíram na publicação da revista sob distintas titulações. Destes, evidenciam-se os autores LOPES, A. B. e RIBEIRO, M. S., que atualmente compõem o quadro docente da USP, porém são advindos dos programas de pós-graduação da referida instituição (Tabela 7).

Tabela 7 - Principais autores na publicação de artigos

\begin{tabular}{lc}
\hline Autores & Número de Trabalhos Publicados \\
\hline MARTINS, E. (USP) & 13 \\
LOPES, A. B. (USP) & 11 \\
GUERREIRO, R. (USP) & 11 \\
CORRAR, Luiz João (USP) & 11 \\
SANTOS, Ariovaldo dos (USP) & 10 \\
BEUREN, I. M. (UFSC/URBL) & 9 \\
PONTE, V. M. R. (UFC/UNIFOR/Universidade de Fortaleza) & 9 \\
CARVALHO, L. Nelson (USP) & 8 \\
ASSAF N., Alexandre (USP) & 8 \\
FREZZATTI, Fábio (USP) & 7 \\
RIBEIRO, M. S. (USP) & 7 \\
\hline
\end{tabular}

Fonte: dados da pesquisa.

A qualidade do periódico vem principalmente dos trabalhos publicados em seus fascículos. Neste sentido, o que se demonstra está relacionado à caracterização teórica na construção dos artigos científicos. Além da própria literatura oferecida nacionalmente, o acréscimo de autores estrangeiros corrobora a destinação de contribuições relevantes à academia no processo de conhecimento.

Tabela 8 - Referências bibliográficas nacionais utilizadas nos trabalhos

\begin{tabular}{lccccccc}
\hline Referências Nacionais & $\mathbf{1 9 8 9}$ & $\mathbf{1 9 9 0}$ & $\mathbf{1 9 9 1}$ & $\mathbf{1 9 9 2}$ & $\mathbf{1 9 9 3}$ & $\mathbf{1 9 9 4}$ & $\mathbf{1 9 9 5}$ \\
\hline Livros & 2 & 1 & 6 & 11 & 20 & 14 & 10 \\
Artigos Eventos e/ou Revistas / Periódicos & 2 & - & - & 5 & 10 & 6 & 11 \\
Leis / Decretos / Constituições / Boletins/ Sites & - & - & - & 7 & 4 & 10 & 3 \\
Teses / Dissertações & 1 & - & - & 7 & 3 & 13 & 3 \\
\hline Referências Nacionais & $\mathbf{1 9 9 6}$ & $\mathbf{1 9 9 7}$ & $\mathbf{1 9 9 8}$ & $\mathbf{1 9 9 9}$ & $\mathbf{2 0 0 0}$ & $\mathbf{2 0 0 1}$ & $\mathbf{2 0 0 2}$ \\
\hline Livros & 18 & 60 & 71 & 46 & 23 & 90 & 71 \\
Artigos Eventos e/ou Revistas / Periódicos & 8 & 10 & 27 & 19 & 8 & 64 & 36 \\
Leis / Decretos / Constituições / Boletins/ Sites & 10 & 12 & 32 & 23 & 7 & 30 & 16 \\
Teses / Dissertações & 9 & 29 & 28 & 38 & 9 & 27 & 38 \\
\hline Referências Nacionais & $\mathbf{2 0 0 3}$ & $\mathbf{2 0 0 4}$ & $\mathbf{2 0 0 5}$ & $\mathbf{2 0 0 6}$ & $\mathbf{2 0 0 7}$ & $\mathbf{2 0 0 8}$ & Dez-09 \\
\hline Livros & 194 & 172 & 130 & 341 & 188 & 166 & 123 \\
Artigos Eventos e/ou Revistas / Periódicos & 51 & 67 & 59 & 90 & 105 & 68 & 88 \\
Leis / Decretos / Constituições / Boletins/ Sites & 65 & 49 & 54 & 55 & 67 & 49 & 44 \\
Teses / Dissertações & 61 & 40 & 39 & 47 & 46 & 28 & 31 \\
\hline Fon
\end{tabular}

Fonte: dados da pesquisa. 
Nas Tabelas 8 e 9 observa-se que, em termos gerais quanto à representatividade da literatura na elaboração dos trabalhos, os autores utilizam em média a mesma quantidade de referências nacionais e internacionais. Porém, no quadro teórico nacional, a maioria dos veículos de divulgação utilizada na produção das publicações do periódico acadêmico se concentra nos livros (50\%), seguidos dos artigos, revistas e periódicos, respondendo a $21 \%$. Já as referencias internacionais utilizadas apresentam-se de maneira distinta, sendo que predominantemente os autores se atêm a construção teórica a partir de artigos, revistas e periódicos, perfazendo 53\%, enquanto os livros respondem a 37\%.

Mais especificamente, observa-se que quando se considera as referências nacionais e internacionais, a utilização reduzida de dissertações ou teses. No caso do material estrangeiro, pode-se levantar a dificuldade na acessibilidade e, conseqüentemente, a obtenção. Já quanto ao manuseio das obras nacionais têm-se uma característica negativa preponderante ao longo do tempo, pois os autores se utilizam dos artigos oriundos dos trabalhos de conclusão dos programas de pós-graduação, em média na revista, $21 \%$, enquanto apenas $14 \%$ são extraídos dos projetos originais. Esta situação direciona-se ao mesmo contexto exposto por Martins (2002), o qual dispõe que o reconhecimento da produção acadêmica produzida pelos próprios programas stricto sensu ainda é baixa, sendo que há reduzidas taxas de referências, e também no cenário de publicações à própria revista considerada neste estudo.

Tabela 9 - Referências bibliográficas internacionais utilizadas nos trabalhos

\begin{tabular}{lccccccc}
\hline Referências Internacionais & $\mathbf{1 9 8 9}$ & $\mathbf{1 9 9 0}$ & $\mathbf{1 9 9 1}$ & $\mathbf{1 9 9 2}$ & $\mathbf{1 9 9 3}$ & $\mathbf{1 9 9 4}$ & $\mathbf{1 9 9 5}$ \\
\hline Livros & - & 1 & - & 82 & 15 & 13 & 5 \\
Artigos Eventos e/ou Revistas / Periódicos & - & - & - & 1 & 11 & 1 & 63 \\
Leis / Decretos / Constituições / Boletins/ Sites & - & - & - & 2 & 2 & - & 4 \\
Teses / Dissertações & - & - & - & - & - & - & - \\
\hline Referências Internacionais & $\mathbf{1 9 9 6}$ & $\mathbf{1 9 9 7}$ & $\mathbf{1 9 9 8}$ & $\mathbf{1 9 9 9}$ & $\mathbf{2 0 0 0}$ & $\mathbf{2 0 0 1}$ & $\mathbf{2 0 0 2}$ \\
\hline Livros & 15 & 39 & 46 & 57 & 30 & 109 & 107 \\
Artigos Eventos e/ou Revistas / Periódicos & 18 & 18 & 33 & 22 & 15 & 78 & 55 \\
Leis / Decretos / Constituições / Boletins/ Sites & 14 & 13 & 13 & 30 & 4 & 48 & 14 \\
Teses / Dissertações & - & - & - & - & 1 & 5 & 1 \\
\hline Referências Internacionais & $\mathbf{2 0 0 3}$ & $\mathbf{2 0 0 4}$ & $\mathbf{2 0 0 5}$ & $\mathbf{2 0 0 6}$ & $\mathbf{2 0 0 7}$ & $\mathbf{2 0 0 8}$ & Dez-09 \\
\hline Livros & 206 & 117 & 82 & 177 & 122 & 95 & 52 \\
Artigos Eventos e/ou Revistas / Periódicos & 161 & 110 & 129 & 318 & 280 & 256 & 395 \\
Leis / Decretos / Constituições / Boletins/ Sites & 44 & 13 & 37 & 43 & 17 & 19 & 28 \\
Teses / Dissertações & - & 3 & 1 & 3 & 4 & 2 & - \\
\hline Fonte: dados pesquisa. & & & & &
\end{tabular}

Fonte: dados da pesquisa.

\subsection{Temática e Metodológica da Revista Contabilidade \& Finanças - USP}

A análise temática das publicações realizadas na Revista de Contabilidade \& Finanças - USP é um meio de notória importância, pois permite visualizar a evolução dos assuntos tratados ao longo da existência do periódico. Para tanto, observa-se as tendências e emergências de aplicações científicas que contribuem de alguma forma, nos trabalhos a serem realizados posteriormente.

Neste estudo, a fim de elencar os principais temas propostos no periódico, utilizou-se os distintos assuntos evidenciados por Martins (2002) e Silva, Oliveira e Ribeiro Filho (2005). Porém, devido à própria evolução entre os estudos considerados, algumas áreas temáticas foram acrescidas (Contabilidade Gerencial e Teoria da Contabilidade).

Para fins de simplificação, percebe-se que predominantemente a Revista apresenta na temática dos trabalhos publicados assuntos relacionados às Finanças e Contabilidade, respondendo a $29 \%$. Nessa direção, verifica-se também, destaque para artigos publicados nas 
áreas de Ensino de Contabilidade e Conhecimento (13\%), Contabilidade Clássica e Teoria da Contabilidade (12\%) e Sistemas de Informação, Comunicação e Evidenciação (11\%).

Quando se considera a análise temporal com o objetivo de demonstrar a predominância de determinados assuntos, em contrapartida a redução de publicações em outras áreas, percebe-se que partindo do período compreendido entre 1989 a 1995, observa-se a concentração de trabalhos nas áreas de Finanças e Contabilidade (17\%), Contabilidade Clássica e Teoria da Contabilidade, Sistemas de Informação, Comunicação e Evidenciação (13\%) e GECON - Sistema de Informação da Gestão Econômica (11\%).

Tabela 10 - Distribuição dos trabalhos publicados por tema

\begin{tabular}{|c|c|c|c|c|c|c|c|}
\hline Temas Abordados & 1989 & 1990 & 1991 & 1992 & 1993 & 1994 & 1995 \\
\hline Ajustes de Valores e Correção Monetária & - & - & - & 1 & 1 & - & - \\
\hline Contabilidade Gerencial & - & - & - & - & - & - & - \\
\hline Sistemas de Informação, Comunicação e Evidenciação & 1 & 2 & 1 & 2 & - & - & - \\
\hline Finanças e Contabilidade & - & - & 1 & 1 & 1 & 5 & - \\
\hline Contabilidade Clássica / Teoria da Contabilidade & 1 & 1 & - & 2 & 2 & - & - \\
\hline Balanço Social e Meio Ambiente & - & - & - & - & 2 & - & - \\
\hline Ensino de Contabilidade e Conhecimento Contábil & - & - & 1 & 1 & - & - & - \\
\hline GECON - Sistema de Informação da Gestão Econômica & - & - & 1 & 3 & 1 & - & - \\
\hline Contabilidade dirigida a Setores & - & 1 & - & - & 1 & 2 & - \\
\hline Auditoria e Perícia Contábil & - & - & - & - & - & - & - \\
\hline Contabilidade de Custos & - & - & - & - & - & - & 2 \\
\hline Planejamento e Gestão Tributária & 1 & - & 1 & 3 & 1 & 1 & - \\
\hline Legislação e Contabilidade & 1 & - & - & - & - & - & 2 \\
\hline Temas Abordados & 1996 & 1997 & 1998 & 1999 & 2000 & 2001 & 2002 \\
\hline Ajustes de Valores e Correção Monetária & 2 & - & - & - & - & - & - \\
\hline Contabilidade Gerencial & - & - & 1 & 1 & - & 2 & 2 \\
\hline Sistemas de Informação, Comunicação e Evidenciação & 1 & - & 5 & 2 & 2 & 5 & 1 \\
\hline Finanças e Contabilidade & 2 & 2 & 4 & 3 & 1 & 3 & 3 \\
\hline Contabilidade Clássica / Teoria da Contabilidade & - & 6 & 3 & 2 & 1 & 1 & 3 \\
\hline Balanço Social e Meio Ambiente & - & - & 1 & - & - & 1 & 1 \\
\hline Ensino de Contabilidade e Conhecimento Contábil & - & - & 2 & 3 & 1 & 3 & 2 \\
\hline GECON - Sistema de Informação da Gestão Econômica & 1 & 1 & 2 & 1 & - & - & - \\
\hline Contabilidade dirigida a Setores & - & 1 & - & - & 1 & 1 & 1 \\
\hline Auditoria e Perícia Contábil & - & - & - & 1 & - & - & 1 \\
\hline Contabilidade de Custos & - & 1 & - & 1 & 2 & - & 2 \\
\hline Planejamento e Gestão Tributária & - & - & - & - & - & - & 1 \\
\hline Legislação e Contabilidade & - & - & 1 & - & - & 1 & 1 \\
\hline Temas Abordados & 2003 & 2004 & 2005 & 2006 & 2007 & 2008 & Dez-09 \\
\hline Ajustes de Valores e Correção Monetária & 1 & - & - & - & - & - & 1 \\
\hline Contabilidade Gerencial & 3 & 2 & 1 & 4 & 2 & 3 & 1 \\
\hline Sistemas de Informação, Comunicação e Evidenciação & 2 & 4 & 2 & 4 & 1 & 2 & 2 \\
\hline Finanças e Contabilidade & 10 & 8 & 10 & 20 & 11 & 7 & 9 \\
\hline Contabilidade Clássica / Teoria da Contabilidade & 9 & 3 & 3 & 2 & 2 & - & 1 \\
\hline Balanço Social e Meio Ambiente & - & 2 & 1 & - & 2 & 1 & 2 \\
\hline Ensino de Contabilidade e Conhecimento Contábil & 5 & 3 & 3 & 2 & 9 & 8 & 1 \\
\hline GECON - Sistema de Informação da Gestão Econômica & 2 & - & - & - & - & - & - \\
\hline Contabilidade dirigida a Setores. & - & - & - & 2 & - & - & 1 \\
\hline Auditoria e Perícia Contábil & 4 & 2 & 1 & 3 & 2 & 2 & 2 \\
\hline Contabilidade de Custos & - & 1 & 1 & 5 & 1 & - & - \\
\hline Planejamento e Gestão Tributária & - & - & 1 & 1 & - & - & - \\
\hline Legislação e Contabilidade & 2 & - & 1 & 1 & - & 2 & 1 \\
\hline
\end{tabular}

Fonte: dados da pesquisa. 
É notório ressaltar, que a preocupação da contribuição à gestão econômica era recorrente nos trabalhos publicados, sendo que se discutia a função dos gestores não se restringindo apenas à execução das atividades sob sua responsabilidade, mas também planejálas e controlá-las. Aos gestores incumbiam-se os processos decisórios operacional, econômico e financeiro (Tabela 10).

Quando se considera o período compreendido entre 1996 e 2009, verifica-se a tendência de alguns temas que se tornaram recorrentes nas publicações anuais do periódico. Destas ressalta-se a Contabilidade Gerencial, o Ensino de Contabilidade e Conhecimento e Auditoria e Perícia Contábil

O crescimento de publicações na Contabilidade Gerencial corrobora as observações dispostas por Oliveira (2002), quando afirma que no Brasil essa tendência só veio ocorrer na década de 90, em que se percebe a importância das informações produzidas pela Contabilidade Gerencial como auxílio na gestão. O desenvolvimento da área temática de Ensino e Conhecimento em Contabilidade está atrelado principalmente, aos artigos onde se investigam as próprias publicações realizadas e os programas de ensino restritos a Ciência Contábil, por exemplo, a variedade de trabalhos bibliométricos, exploratórios e metanálise.

Quanto à emergência de assuntos publicados sobre Auditoria e Perícia Contábil, podese ressaltar principalmente como marco dessa preocupação acadêmica os escândalos das organizações World Com e Eron, em meados de 2002. Esse cenário trouxe a criação da Lei Sarbanes-Oxley nos Estados Unidos, em que se tornou um objetivo premente de estudo aos pesquisadores, além disso, foi constante a proposição de estudos relacionando-se a aplicabilidade na legislação brasileira.

As temáticas apresentadas têm um mesmo direcionamento dos trabalhos elaborados por Martins (2002), Mendonça Neto et al. (2004), Silva, Oliveira e Ribeiro Filho (2005), Espejo et al. (2009), que apontam o crescente desenvolvimento de pesquisas nas áreas de ensino e contabilidade gerencial. Entretanto, não foi observada a participação representativa de assuntos publicados sobre auditoria e perícia contábil, mas a preocupação cada vez mais relevante quanto à Teoria da Contabilidade. Oliveira (2002) demonstra esta tendência nos cursos de pós-graduação, pois na graduação esta disciplina ainda é recente na grade curricular.

Outro elemento relevante na análise dos trabalhos publicados no periódico trata dos procedimentos metodológicos. A metodologia consiste em definir onde e como será realizada a pesquisa, implica na escolha de estratégias para conduzir os trabalhos de investigação. A definição do método a ser empregado participa do processo da metodologia, que escolhe um conjunto de procedimentos disponíveis, o melhor a ser utilizado.

Para tanto, considerou-se a distinção proposta por Gil (1999) e Andrade (2002), quanto aos fins e aos meios de pesquisa. Considerando os fins da pesquisa, referindo-se aos objetivos gerais, pode-se classificá-los em descritivos, exploratórios e explicativos. Na análise do periódico elucida-se que a maioria dos trabalhos apresenta-se como descritivo; seguidos de estudos exploratórios. Vale ressaltar que os artigos publicados, principalmente de 1989 a 2000, demonstravam-se pouco preocupados com a evidenciação metodológica. Não se observava tópicos nas pesquisas de indicação dos procedimentos metodológicos, independentemente de como eram realizados.

Quando se considera os meios de pesquisa, pode-se observar a distinção verificada entre os períodos da publicação. Considerando os anos compreendidos entre 1989 a 1995, observa-se que predominantemente as pesquisas eram revisões bibliográficas (35\%) e estudos didáticos $(22 \%)$. É notório destacar a endogenia desses artigos, pois na maioria não necessitavam de um rigor metodológico maior, pois se tratavam de works papers dos professores afiliados a USP e, ainda, trabalhos oriundos das próprias disciplinas dos programas de pós-graduação da Universidade de São Paulo.

Entre 1996 a 2002 percebe-se ainda uma concentração de trabalhos realizados de 
cunho bibliográfico. Porém, neste período há um destaque para estudos documentais (22\%) e, aqueles que se utilizam de dados primários e/ou secundários para pesquisas empíricas $(10 \%)$. A classificação como análise documental representa estudos baseados em documentos não elaborados. Gil (1999) classifica a pesquisa como documental em razão de se basear em materiais que podem ser reelaborados de acordo com os propósitos apresentados, sendo que a pesquisa documental baseia-se em materiais que ainda não receberam um tratamento analítico ou que podem ser reelaborados de acordo com os objetivos da pesquisa.

Neste cenário, os trabalhos publicados na revista atendem a esta definição, pois na maioria se utilizam de Leis, Decretos, Boletins, Convenções e Relatórios para a realização dos estudos. Ressalta-se informações obtidas na Comissão de Valores Mobiliários (CVM), International Accounting Standards Committee (IASC), International Financial Reporting Standards Board (IASB), US Securities and Exchange Commission (SEC) e a Lei n. 11.638/ 2007 - Lei das Sociedades por Ações.

Tabela 11 - Tipologia metodológicas de estudos

\begin{tabular}{|c|c|c|c|c|c|c|c|}
\hline Quanto aos meios de pesquisa & 1989 & 1990 & 1991 & 1992 & 1993 & 1994 & 1995 \\
\hline Revisão de bibliografia & 2 & 1 & 2 & 6 & 2 & 2 & 1 \\
\hline Didático & 1 & 2 & - & 2 & 3 & 1 & 1 \\
\hline Proposta / Análise de modelo teórico & - & - & - & 2 & - & 1 & - \\
\hline Crítico-reflexivo & - & - & - & - & 1 & - & - \\
\hline Teórico-Empírico com dados primários e/ou secundários & 1 & - & 2 & - & - & 1 & - \\
\hline Levantamento & - & - & - & - & - & - & - \\
\hline Estudo de caso & - & - & - & 1 & 1 & 3 & - \\
\hline Pesquisa-ação & - & - & - & - & - & - & - \\
\hline Proposta / Análise de modelo empírico & - & - & - & 2 & 1 & - & 1 \\
\hline Documental & - & 1 & - & - & 1 & - & 1 \\
\hline Quanto aos meios de pesquisa & 1996 & 1997 & 1998 & 1999 & 2000 & 2001 & 2002 \\
\hline Revisão de bibliografia & 2 & 7 & 12 & 4 & 2 & 3 & 8 \\
\hline Didático & 2 & 2 & 2 & 1 & - & 1 & - \\
\hline Proposta / Análise de modelo teórico & - & 2 & 1 & 2 & - & - & - \\
\hline Crítico-reflexivo & 2 & - & - & 2 & - & 2 & - \\
\hline Teórico-Empírico com dados primários e/ou secundários & - & - & - & 2 & 1 & 3 & 3 \\
\hline Levantamento & - & - & 1 & - & - & 1 & 3 \\
\hline Estudo de caso & - & - & - & - & - & 1 & - \\
\hline Pesquisa-ação & - & - & - & - & - & - & - \\
\hline Proposta / Análise de modelo empírico & - & - & - & - & 1 & - & - \\
\hline Documental & - & - & 3 & 3 & 4 & 6 & 4 \\
\hline Quanto aos meios de pesquisa & 2003 & 2004 & 2005 & 2006 & 2007 & 2008 & Dez-09 \\
\hline Revisão de bibliografia & 16 & 7 & 6 & 9 & 2 & 1 & 3 \\
\hline Didático & 1 & - & - & - & - & - & - \\
\hline Proposta / Análise de modelo teórico & - & - & - & 1 & - & 1 & 1 \\
\hline Crítico-reflexivo & - & - & - & - & 1 & - & - \\
\hline Teórico-Empírico com dados primários e/ou secundários & 7 & 12 & 9 & 27 & 18 & 14 & 13 \\
\hline Levantamento & 1 & 1 & 3 & 2 & 2 & 3 & 1 \\
\hline Estudo de caso & 8 & 4 & 2 & 3 & 1 & 3 & 3 \\
\hline Pesquisa-ação & 1 & - & - & - & - & - & - \\
\hline Proposta / Análise de modelo empírico & - & - & - & - & 2 & 1 & - \\
\hline Documental & 4 & 1 & 4 & 2 & 3 & 3 & 1 \\
\hline
\end{tabular}

Fonte: dados da pesquisa.

No período de 2003 a 2009 há notória elevação de estudos empíricos realizados a partir de dados primários e/ou secundários. O que demonstra uma apresentação metodológica 
mais apurada, sendo desenvolvidos meios de coleta, identificação e análise dos dados, voltados à contribuição prática na ciência. Ressalta-se a aplicabilidade de técnicas como entrevistas, questionários e a utilização de banco de dados financeiros, de distintas fontes, como o Tesouro Nacional, a BOVESPA e o software Economática ${ }^{\circledR}$. Neste período, os artigos quanto aos procedimentos metodológicos eram bem mais delineados, com distinção quanto aos meios e aos fins da pesquisa e, principalmente, a descrição do caminho percorrido no estudo desde o levantamento dos dados à aplicabilidade de tratamentos ou representações de modelos (Tabela 11).

\section{CONCLUSÕES}

A pesquisa contábil no Brasil tem apresentado um crescimento notório nos últimos anos, principalmente no que concerne a fatores relacionados a novos programas de pósgraduação stricto sensu e da oferta dos cursos de especialização. Além disso, observa-se a evolução dos meios de divulgação científica, na forma de encontros, seminários, congressos e periódicos científicos.

Considerando a importância da pesquisa contábil, atualmente tem-se utilizado um processo de avaliação para o entendimento da produção científica, especificamente de elementos relacionados às suas características, constituídas de dados de autoria, citação, referências, métodos, dentre outros. Neste contexto tem-se verificado a evolução dos estudos relacionados a resultados avaliativos sobre o produto científico na área de Contabilidade e Finanças. É oportuno ressaltar a contribuição desses trabalhos na consolidação, explicação, discussão e reflexão de cientificidade nessa área.

Como um dos veículos de presente notoriedade às áreas de Ciências Contábeis e Finanças, este estudo considerou a avaliação da Revista Contabilidade \& Finanças da Universidade de São Paulo. Para ressaltar a importância desse periódico, vale lembrar que possui 20 anos de existência e é qualificado pela CAPES como B1.

Partindo-se da análise de características relacionadas às dimensões do número de páginas e fascículos, número de autores por artigo, filiação acadêmica, titulação acadêmica, autores mais representativos, referências utilizadas, instituições, temática e metodologia aplicada, observou-se que a revista nos primeiros anos de publicação restringia-se a poucos trabalhos e de edições reduzidas. Considera-se um marco do periódico o ano de 2001, em que passou a apresentar periodicidade constante e maior abertura à adesão de distintos autores.

A contribuição de autores para o desenvolvimento do periódico pode ser distinguida entre dois períodos; de 1989 a 2002, em que se verificou a predominância de docentes ou discentes afiliados a USP, apresentando-se com maioria absoluta nas publicações. Entretanto, de 2003 a 2009, a contribuição de outras entidades a revista tornou-se notória, representando aproximadamente $73 \%$ do total de autores. Destacam-se como principais entidades nas publicações dos estudos, a PUC, a FUCAPE, a UFRJ e a UFC.

A endogenia do período entre 1989 a 2002 é representativa, principalmente de autores da USP, pois esta instituição é pioneira nos programas de pós-graduação em Contabilidade e Finanças. Estes programas exigem elevada produção científica e contribuições ao meio acadêmico. Além disso, apesar da significativa quantidade de cursos de Ciências Contábeis no Brasil, a graduação pouco contribuiu para a pesquisa.

Em contrapartida, no período de 2003 a 2009 verificou-se uma diminuição na concentração de autores dos trabalhos publicados na Revista de Contabilidade \& Finanças USP, o que é positivo para a evolução da área. Esta constatação refere-se ao desenvolvimento de programas lato e stricto sensu em Contabilidade e Finanças de outras instituições, citam-se a Universidade Federal de Minas Gerais (UFMG), a Universidade Federal do Rio de Janeiro (UFRJ), a Universidade Federal do Paraná (UFPR), a Fundação Capixaba de Pesquisa em Administração, Contabilidade e Economia (FUCAPE), a Pontifícia Universidade Católica 
(PUC), a Universidade Federal do Ceará (UFC) e a Universidade de Brasília (UnB).

Outro aspecto observado neste estudo refere-se à contribuição dos autores quanto à titulação. Verificou-se a concentração na publicação de professores; destes, a maioria representava doutores ou doutorandos. A participação de discentes relacionados a programas de pós-graduação, também se considerou notória, em contrapartida percebeu-se pouca representatividade ao nível de graduação. Uma restrição a esta observação é que, os docentes podem estar vinculados a outras instituições e os autores modificaram sua titulação.

A temática observada na análise do periódico permitiu verificar a evolução dos assuntos evidenciados em Contabilidade ao longo de 20 anos. Para fins de simplificação, percebeu-se a predominância de estudos relacionados a Finanças e Contabilidade (29\%), Ensino de Contabilidade e Conhecimento (13\%), Contabilidade Clássica e Teoria da Contabilidade (12\%) e Sistemas de Informação, Comunicação e Evidenciação (11\%). Vale ressaltar que a composição destes trabalhos apresentaram-se de distintas fontes, sejam estas nacionais e internacionais, dando destaque a utilização de livros, artigos e periódicos científicos, entretanto observou-se reduzida consulta a trabalhos oriundos dos programas de mestrado ou doutorado.

Um aspecto importante observado refere-se aos procedimentos metodológicos evidenciados nos artigos. Percebeu-se quanto aos fins, a endogenia de trabalhos descritivos, principalmente no que concerne aos primeiros anos da revista. Quanto aos meios, notou-se entre 1989 a 2002, uma concentração de publicações de cunho bibliográfico e documental. Já, entre 2003 e 2009, o cenário é distinto, predominando estudos realizados com aporte de dados primários e/ou secundários, podendo-se classificá-los como empíricos.

Além disso, na análise do periódico no que concerne à metodologia, pode-se considerar que a disposição dos artigos quanto aos procedimentos metodológicos tornaram-se bem mais delineados. Particularmente em assertivas de distinção quanto aos meios e aos fins da pesquisa e, principalmente, a descrição do caminho percorrido no estudo desde o levantamento dos dados à aplicabilidade de tratamentos ou representações de modelos.

É relevante ainda destacar que, a análise apontou uma possível tendência na publicação de artigos em Ensino e Conhecimento e Teoria Contábil de maneira prática e empírica por meio de modelos em dados primários e/ou secundários. A explicação se deve principalmente às constantes modificações devido a uniformização contábil mundial, que exige interpretações do impacto no patrimônio das entidades. $O$ conhecimento dos pronunciamentos contábeis (CPC) e das normas expedidas na International Financial Reporting Standards (IFRS) torna-se cada vez mais importante.

Diante do exposto, observa-se a importância que o periódico em estudo adquiriu. Sendo que se tornou principalmente um meio que permite avaliar e elencar a pesquisa relacionada à Contabilidade e Finanças. Por meio deste estudo é válido ressaltar a importância das pesquisas contábeis para o crescimento dos estudos na área. Além disso, a necessidade de observar nos estudos questões relacionadas aos aspectos metodológicos, temáticos, referenciais, dentre outros das publicações, visto que esses ainda não são temas muito abordados na área acadêmica contábil e de alguma forma podem contribuir cada vez mais à realização de novas pesquisas.

\section{REFERÊNCIAS}

ANDRADE, M. M. Como preparar trabalhos para cursos de pós-graduação: noções práticas. 5. ed. São Paulo: Atlas, 2002.

ASTI VERA, A. Metodologia da pesquisa científica. Porto Alegre: Globo, 1983.

BARDIN, L. Análise de conteúdo. Lisboa, Portugal: Edições 70, 1977. 
BORBA, J. A.; MURCIA, F. D. Oportunidades para pesquisa e publicação em contabilidade: um estudo preliminar sobre as revistas acadêmicas de língua inglesa do portal de periódicos da CAPES. Brazilian Business Review, v. 3, n. 1, jan./jun. 2006.

BRUYNE, P.; HERMAN, J.; SCHOUTHEETE, M. Dinâmica da pesquisa em ciências sociais: os pólos da prática metodológica. Trad. de RuthJoffily. Rio de Janeiro, Francisco Alves, 1991.

CARDOSO, R. L.; MENDONÇA NETO, O. R. O.; RICCIO, E. L.; SAKATA, M. C. G. Pesquisa científica em contabilidade entre 1990 e 2003. RAE. Revista de Administração de Empresas, v. 43, jun. 2005. http://dx.doi.org/10.1590/S0034-75902005000200004

CHUNG, K. H.; COX, R. A. K. Patterns of research output in the accounting literature: study of the bibliometric distribution. Abacus, v. 28, n. 2. p. 168-183. 1992. http://dx.doi.org/10.1111/j.1467-6281.1992.tb00278.x

DEMO, P. Metodologia do conhecimento científico. São Paulo: Atlas, 2000.

DUARTE, E. N.; SILVA, E. P. da; ZAGO, C. C. Tendências da produção científica em gestão do conhecimento. Disponível em: <www.google.com.br>. Acesso em: 14 out. 2009.

ESPEJO, M. M. S. B.; DA CRUZ, A. P. C.; LOURENÇO, R. L.; ANTNOVZ, T.; ALMEIDA, L. B. Estado da arte da pesquisa contábil: um estudo bibliométrico de periódicos nacional e internacionalmente veiculados entre 2003 e 2007. Revista de Informação Contábil, v. 3, n. 3, p. 94-116, jul./set. 2009.

FOGARTY, T. J. Sustained research productivity in Accounting: a study of the senior cohort. Global Perspectives in Accounting Education, v. 1, p. 31-58, 2004.

GIL, A. C. Como elaborar projetos de pesquisa. 3. ed. São Paulo: Atlas, 1996.

LAKATOS, E. M.; MARCONI, M. A. Fundamentos de metodologia científica. 4. ed. São Paulo: Atlas, 2001.

LEAL, R. P. C.; OLIVEIRA, J.; SOLURI, A. F. Perfil da pesquisa em finanças no Brasil. RAE. Revista de Administração de Empresas, v. 43, n. 1, mar. 2003. http://dx.doi.org/10.1590/S0034-75902003000100010

LEAL, R. P. C.; PAULO JUNIOR, J.; SIQUEIRA, R. L. Estudo do referencial bibliográfico da produção científica dos periódicos e anais de congressos na área de contabilidade no Brasil: uma análise bibliométrica de 1999 a 2004. Relatório Final de Pesquisa. Unimontes, Pró-Reitoria de Pesquisa, 2006.

LEITE FILHO, G. A. Padrões de produtividade de autores em periódicos e congressos na área de contabilidade no Brasil: um estudo bibliométrico. RAC. Revista de Administração Contemporânea, v. 12, n. 2, p. 533-554, abr./jun. 2008. http://dx.doi.org/10.1590/S141565552008000200011

LEHFELD, N. A. S.; BARROS, A. J. S. Fundamentos de metodologia científica: um guia para a iniciação científica. 2. ed. São Paulo: Makron Books, 2000.

LUCENA, W. G.; CAVAlCANTE, P. R. N.; SALES, L. B. O perfil das dissertações do Programa Multi-institucional e Inter-regional de Pós-Graduação em Ciências Contábeis UnB/UFPB/UFRN/UFPE. In: EnANPAD, 31., 2007, Rio de Janeiro. Anais... Rio de Janeiro: ANPAD, 2007. CD-ROM.

KRZYZANOWSKI, R.; FERREIRA, M. C. G.. Avaliação de periódicos científicos e técnicos brasileiros. Ciência da Informação, Brasília, v. 27, n. 2, p. 165-175, 1998. http://dx.doi.org/10.1590/S0100-19651998000200009 
MALHOTRA, N. Pesquisa de marketing: uma orientação aplicada. 3. ed. Porto Alegre: Bookman, 2001.

MARTINS, G. A. Manual para elaboração de monografias e dissertações. 2. ed. São Paulo: Atlas, 1994.

MENDONÇA NETO, O.R.; CARDOSO, R.L.; RICCIO; E.L.; SAKATA, M.C.G. Estudos sobre as publicações científicas em contabilidade: uma análise de 1990 até 2003. Disponível em: <http://www.anpad.org.br/enampad/2004- ccg-1854.pdf>. Acesso em: 10 out. 2009.

MORIKI, A. M. N.; MARTINS, G. A. Análise do referencial bibliográfico de teses e dissertações sobre contabilidade e controladoria. In: CONGRESSO USP DE CONTABILIDADE E CONTROLADORIA, 3., 2003, São Paulo. Anais... São Paulo: FEA/USP, 2003.

OLIVEIRA, M. C. Análise dos periódicos brasileiros de contabilidade. Revista Contabilidade \& Finanças - USP. São Paulo, n. 29, p. 68-86, maio/ago. 2002. http://dx.doi.org/10.1590/S1519-70772002000200005

PROGRAMA INSTITUCIONAL DE BOLSAS DE INICIAÇÃO CIENTÍFICA (PIBIC). Resolução Normativa n. 019/2001. Disponível em: 〈www.cnpq.br/areas/pibic/rn019-01.htm〉. Acesso em: 05 nov. 2009.

QUALIS CAPES. Revista Contabilidade e Finanças - USP. Disponível em: <http://qualis.capes.gov.br/>. Acesso em: 10 out. 2009.

RODGERS, J. L.; WILLIANS, P. F. Patterns of research productivity an knowledge creation at the accounting review: 1967-1993. The Accounting Historians Journal, v. 1, jun. 1996.

SANTANA, C. M. Produção do conhecimento em contabilidade social no Brasil (1990 a 2003): uma abordagem bibliométrica. Dissertação (Mestrado em Controladoria e Contabilidade) - Programa de Pós-Graduação em Ciências Contábeis, FEA/USP, São Paulo, 2004.

SCHWARTZMAN, S. A política brasileira de publicações científicas e técnicas: reflexões. Revista Brasileira de Tecnologia, v. 15, n. 3, p. 25-32, maio/jun., 1984.

SEVERINO, A. J. Metodologia do trabalho científico. São Paulo: Cortez, 1996.

SILVA, A. C. R. Metodologia da pesquisa aplicada à contabilidade: orientações de estudos, projetos, relatórios, monografias, dissertações, teses. São Paulo: Atlas, 2003.

SILVA, A. C. B.; OLIVEIRA, E. C.; RIBEIRO FILHO, J. F. Uma comparação entre os períodos da Revista Contabilidade \& Finanças - USP: 1998/2001 e 2001/2004. Revista Contabilidade \& Finanças, n. 39, p. 20-32, set./dez., 2005. http://dx.doi.org/10.1590/S151970772005000300003

ZEFF, S. A. A study of academic research journals in accounting. Accounting Horizons. v. 10, n. 3, p. 159-177, Sep. 1996. 